\title{
Comparative Evaluation of The Protective Efficacy of Different Vaccination Programs Against a Virulent Field Strain of the Newcastle Disease Virus in Broilers
}

EAuthor(s)

\author{
Sarcheshmei $M^{\prime}$ \\ Dadras H" \\ Mosleh N" \\ Mehrabanpour MJ"I
}

PhD student, Department of Clinical Studies, School of Veterinary Medicine, Shiraz University, Shiraz, Iran

" Department of Clinical Studies, School of Veterinary Medicine, Shiraz University, Shiraz, Iran

II Razi Vaccine and Serum Research Institute, Shiraz, Iran

\section{ABSTRACT}

Despite the intensive vaccination programs used for controlling Newcastle disease (ND) in the Iranian poultry industry, outbreaks of ND have been reported in poultry farms. This study was conducted to evaluate the effectiveness of vaccines for the protection against ND infection and virus-shedding period of velogenic Newcastle disease virus (vNDV) field strain after different immunization schemes. Eight groups of commercial broiler chickens were used. Six groups were vaccinated with different vaccination programs using commercial live and inactivated ND vaccines. All groups, except for group 8 , were challenged with a virulent field isolate (104EID50/bird) at 28 days of age. Clinical signs, mortality rate and gross lesions were investigated. Antibody titers were assayed by hemagglutination inhibition test and fecal virus shedding was determined for 14 days post challenge (dpc) with 3-day intervals by the RT-PCR method. All unvaccinated-challenged control birds died. Vaccination with these ND vaccines protected chickens from clinical disease. The mortality rate in the vaccinated groups was significantly lower than in the positive control group. However, vaccinated chickens shed the challenge virus in fecal samples. Although the different vaccination regimens displayed close degrees of protection against the disease, the best protection was observed in broilers primed with the live B1 vaccine via eye drop simultaneously with inactivated vaccine at 8 days of age and boosted with B1 or LaSota via drinking water on day 18 . In conclusion, the currently used vaccines with different vaccination schemes can protect chickens against the disease in areas where ND is endemic, while the spread of the field virus to other flocks cannot be prevented.

\section{INTRODUCTION}

Newcastle disease, which is caused by Newcastle disease virus (NDV), is one of the most serious infectious diseases affecting birds, particularly poultry, and can lead to serious economic losses (Aldous et al., 2003). NDV is classified as a member in the Avulavirus genus, within the Paramyxoviridae family. NDV isolates are classified as lentogenic (low), mesogenic (intermediate), or velogenic (highly virulent), depending on the severity of the disease produced by the isolate in chickens (Alexander, 1997). NDV has been the cause of significant outbreaks in poultry (Alexander et al., 2012). The virus is highly transmissible in poultry with low antibody titers (Boven et al., 2008). There have been several panzootics of this serious disease in poultry during the last four decades (Alexander, 2011) and the velogenic strains are now endemic in the commercial poultry farms of many countries (Boney et al., 1975, Giambrone \& Closser, 1990), including Iran.

Vaccination and biosecurity are widely used as management practices for the protection against ND virus. Vaccination policies vary 
in different countries (Patti \& Koch, 2013). In most areas of Iran where NDV is endemic, vaccination is mandatory for commercial and backyard poultry. Vaccination with different low-virulence live vaccine strains, such as B1 and LaSota, has been extensively used in Iranian commercial farms. The inactivated oil-emulsified vaccine has also been used in most regions of the country. Despite frequent vaccination, the high mortality and economical losses show that vaccination strategies were not able to completely prevent outbreaks against the currently circulating viruses. This represents a major problem for the poultry industry and therefore, further investigation on vaccines and vaccination programs to prevent and control this disease more appropriately is required.

The aim of the present study was to evaluate the protective effect of vaccines (B1, LaSota, and inactivated vaccines) against velogenic ND infection in broilers after different vaccination schemes. Since a proper vaccine or vaccination program should be able to reduce virus shedding and virus spread among chickens, the virus shedding period of the vNDV field isolate was also evaluated. The conclusions are helpful in that we are able to determine the best scheme (type of vaccines, strains of vaccines, age and route of vaccination) for commercial broilers to obtain the least morbidity, mortality and least amount of shedding of virulent challenge virus.

\section{MATERIALS AND METHODS}

\section{Challenge virus}

A highly-virulent NDV field strain (Gene bank accession Number: JF820294.1) was used. The intravenous pathogenicity index of the challenge virus was 2.46. It was propagated in 9- to 10-dayold embryonated chicken eggs via the allantoic route, titrated, and stored at $-70{ }^{\circ} \mathrm{C}$ until use. The embryo infective dose (EID50) was determined as described by Reed and Muench (1938), and was determined as $10^{8.3} / \mathrm{mL}$ of allantoic fluid.

\section{Vaccines and antigens}

Lentogenic NDV vaccines B1 (Batch number 34490019) and LaSota (Batch number 34390024) strains, and inactivated ND + Al (Batch number 2670093) vaccine produced by the Razi Vaccine and Serum Research Institute (Iran) were used to vaccinate chickens. The ND standard antigen used for serological tests was provided by Pasouk Biologicals Research and Manufacturing Company, Iran.

\section{Experimental design}

One hundred sixty mixed sex one-day-old commercial broiler chickens (Cobb 500) were purchased from a local hatchery and randomly allocated into eight groups of 20 chicks each. The birds of each group were reared in the separate isolated rooms. Birds in all groups had access to feed and water ad libitum throughout the experiment.

The vaccination schedule (based on the local advised programs) was as follows:

Group 1: B1 via eye drop at 8 days of age followed by $\mathrm{B} 1$ via drinking water at 18 days of age.

Group 2: B1 via eye drop at 8 days of age followed by LaSota via drinking water at 18 day of age.

Group 3: B1 via eye drop at day old followed by B1 via drinking water at 18 day of age.

Group 4: B1 via eye drop at day old followed by LaSota via drinking water at 18 day of age.

Group 5: B1 via spray route at day old followed by $B 1$ via drinking water at 18 day of age.

Group 6: B1 via spray route at day old followed by LaSota via drinking water at 18 day of age.

All chicks in these groups received ND+Al inactivated vaccine via subcutaneous route at 8 days of age. Groups 7 and 8 were the positive and negative control groups, respectively, and did not receive any vaccine. On day 28, all groups, except for group 8, were challenged with the virulent field isolate virus via intranasal route $\left(10^{4}\right.$ EID50/bird). Following challenge, birds were monitored daily for the development of either clinical signs of the disease or mortality and tested for shedding of the challenge virus. Fecal samples from five birds per group were randomly collected at 3-day intervals during $14 \mathrm{dpc}$ for the evaluation of the virus shedding period.

Dead or euthanized birds (at least three carcasses) were necropsied 5, 10 , and 14 days after challenge. Lesions were scored for severity in a scale of 0 to +4 by one person. A score of 0 was assumed for tissues without any gross lesions. Scores 1 to 4 was given to mild, intermediate, severe and very severe lesions, respectively. The severity index was then calculated as follows: ( $\Sigma$ number of birds with lesions $\times$ severity score) / (number of sampled birds). Serum samples were collected when birds were $1,8,15$ and 22 days of age and on 0, 5, 10 and $14 \mathrm{dpc}$ to determine antibody titers against NDV by hemagglutination inhibition $(\mathrm{HI})$ test.

\section{HI test}

The hemagglutination $(\mathrm{HA})$ and $\mathrm{HI}$ tests were performed using standard microtiter plate methods. 
The $\mathrm{HI}$ tests were carried out with $4 \mathrm{HA}$ units per well with two-fold serum dilutions, as recommended by the World Organization for Animal Health (OIE, 2012).

\section{Reverse Transcription PCR}

Vaccinal or virulent virus detection was performed by reverse transcription polymerase chain reaction (RT$P(R)$ method. The RNA isolation process was carried out with $100 \mu \mathrm{L}$ of clarified $10 \%$ fecal suspension in normal saline with RNX ${ }^{\mathrm{TM}}$-Plus kit (CinnaGen Co., Iran) according to manufacturer's protocol. RNA was eluted with $50 \mu \mathrm{L}$ distilled water and either stored at $-70^{\circ} \mathrm{C}$ or directly used for cDNA synthesis. The CDNA synthesis process was performed with AccuPower ${ }^{\circledR}$ RT-PCR kit (Bioneer Co., South Korea). Ten pmol/ $\mu \mathrm{L}$ of forward (B or $C$ ) and reverse (A) primer pair (Table 1) were used for CDNA synthesis.

Table 1 - Oligonucleotides used for RT-PCR (Baratchi et al., 2006).

\begin{tabular}{ll}
\hline Primer & Sequence \\
\hline A (R) & 5'-TTGATGGCAGGCCTCTTGC-3' $^{\prime}$ \\
\hline B (F) & 5'-AGCGTCT-CTGTCTCCT-3' $^{\prime}$ \\
\hline C (F) & 5'-G(A/G)CG(AT)-CCCTGT(C/T)TCCC-3' $^{\prime}$ \\
\hline
\end{tabular}

Five $\mu \mathrm{L}$ of the CDNA was used for PCR amplification using AccuPower ${ }^{\circledR}$ PCR PreMix (Bioneer Co., South Korea) with two different primer pairs $A+B$ and $A$ $+C$ (Table 1), which yield specific amplification of a $255 \mathrm{bp}$ fragment within the $F$ gene. We were able to differentiate virulent virus from vaccine viruses. The vaccine virus strains were amplified only by $A+C$ primer pairs, while virulent strains of NDV was amplified by both primer pairs $(A+B$ and $A+C)$ (Fig 1.). After denaturation for $3 \mathrm{~min}$ at $94^{\circ} \mathrm{C}$, the PCR consisted of 30 cycles of $30 \mathrm{~s}$ at $94^{\circ} \mathrm{C}, 30 \mathrm{~s}$ at $58^{\circ} \mathrm{C}$ and $30 \mathrm{~s}$ at $72^{\circ} \mathrm{C}$ that was terminated by $10 \mathrm{~min}$ at $72^{\circ} \mathrm{C}$. Samples were analyzed by electrophoresis on $1.5 \%$ agarose gel and visualized under ultraviolet light.

\section{Statistical analysis}

$\mathrm{HI}$ results were analyzed with a statistical software program (SPSS Inc., 11.5). Analysis of variance (ANOVA) using pair-wise comparisons by Tukey's test was used to compare $\mathrm{HI}$ mean values (differences were considered significant at $p \leq 0.05$ ). Chi-square or Fisher's exact test was used to analyze the association of mortality and viral fecal shedding with each vaccination program on each day, for each two desired groups. $P$ values obtained by a Pearson's Chi-square association or Fisher's exact test were considered as significant when $p<0.05$.
Figure 1 - RT-PCR products (255 bp) amplified from velogenic or vaccine NDV strains with two different primer pairs $(A+B \& A+C)$ and visualized following electrophoresis on ethidium bromide stained $1 \%$ agarose gel.

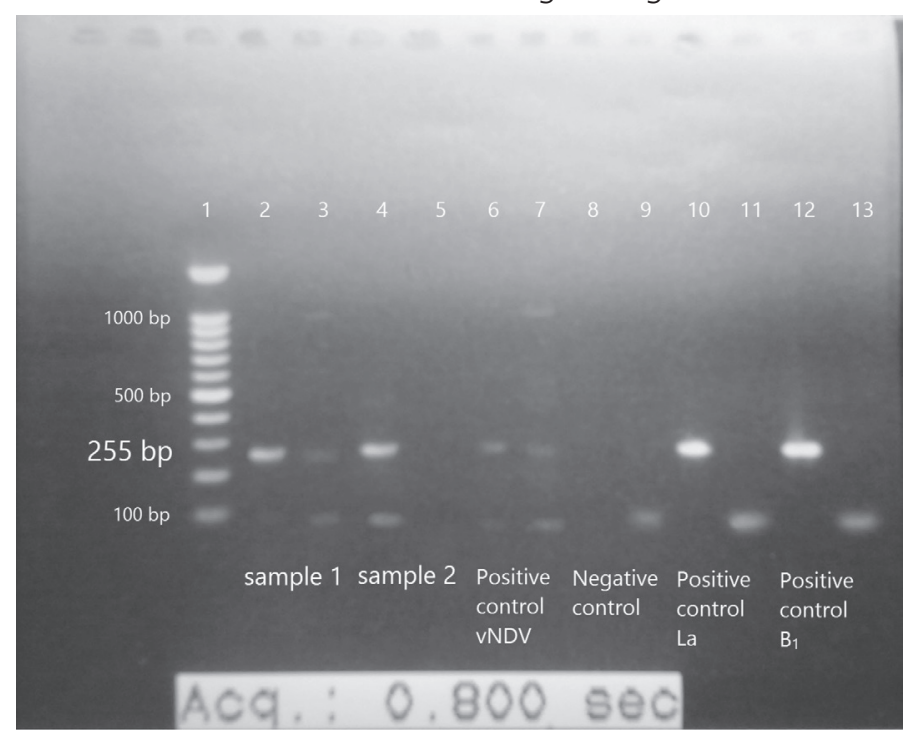

Lane 1: DNA marker (100bp); Lane 2 \& 3: Sample 1 by using $A+C$ primers (lane 2 ) and $A+B$ primers (Lane 3 ); Lane $4 \& 5$ : Sample 2 by using $A+C$ primers (lane 4 ) and $A+B$ primers (Lane 5). Lane $6 \&$ 7: Positive controls (Velogenic NDV) by using $A+C$ (lane 6) and $A+B$ (lane 7) primers; Lane $8 \&$ 9: Negative controls by using $A+C$ primers and $A+B$ primers, respectively. Lane 10 \& 11: Positive controls of LaSota strain by using $A+C$ primers (lane 10) and $A+B$ primers (lane 11); Lane $12 \& 13$ : Positive controls of $B 1$ strain by using $A+C$ and $A+B$ primers, respectively. The vaccine virus strain could be amplified by $A+C$ primer pairs while virulent strains of NDV could be amplified by both primer pairs $(A+B$ and $A+C)$.

\section{RESULTS}

\section{Clinical signs and mortality}

All birds were apparently healthy before challenge. Protection from velogenic virus challenge was determined by the absence of clinical signs during the $14 \mathrm{dpc}$ observation period. Birds in the unchallenged control group (group 8) had no clinical signs during the course of the experiment. All birds in the challenged control group (group 7) displayed conjunctivitis, severe depression, respiratory signs, greenish diarrhea, ruffled feathers, and reduced feed intake from day 3 pc.

Chickens in the vaccinated-challenged groups showed significantly weaker clinical signs compared with the positive control group. Leg paralysis was observed in $10 \%$ of chickens in groups 1,5 , and 6 from day 5 pc, while only $5 \%$ of birds in groups 2,3 and 4 showed leg paralysis. Five percent of chickens in groups 2, 3 and 5 , as well as $15 \%$ of birds in group 6 , showed torticollis. The frequency of clinical signs was statistically the same among the different groups. 
No mortality was observed in negative control group, while all birds in positive control group died during the course of the experiment. The mortality rate of the vaccinated groups was significantly lower than the positive controls. No significant difference was observed among groups 1 (0\%), 2 (5\%), 4 (10\%), 6 $(15 \%)$, and the negative control group. All vaccinated groups statistically presented the same mortality rate (except group1) and the lowest mortality rate was recorded in group 1, followed by groups 2, 4, and 6 . The highest mortality rate $(25 \%)$ among vaccinated groups was observed in group 3 and 5, and was significantly higher than group 1 and the negative control group.

\section{Necropsy findings}

At necropsy, gross lesions were not observed in any birds of negative control group (group 8). Most chickens in group 7 (unvaccinated-challenged) exhibited typical visceral lesions, similar to natural field cases from day 3 pc. Chickens of this group showed hemorrhagic lesions in the proventriculus (Fig. 2), cecal tonsils (Fig. 3) and Peyer's patches of the intestines (Fig.4). Lesions in the respiratory tract, including edematous, hemorrhagic and congested trachea, were also seen in this group (Fig.5). The most severe gross lesions in the positive control group were observed from day 5 to 8 pc. The highest lesion scores were recorded in the proventriculus, intestine, cecal tonsils and trachea. Groups 1 and 2 showed the best protection among vaccinated groups during this period, followed by groups 6, 5, 4 and 3 (data not shown).

Figure 2 - Representative samples showing different severity scores in proventriculus.

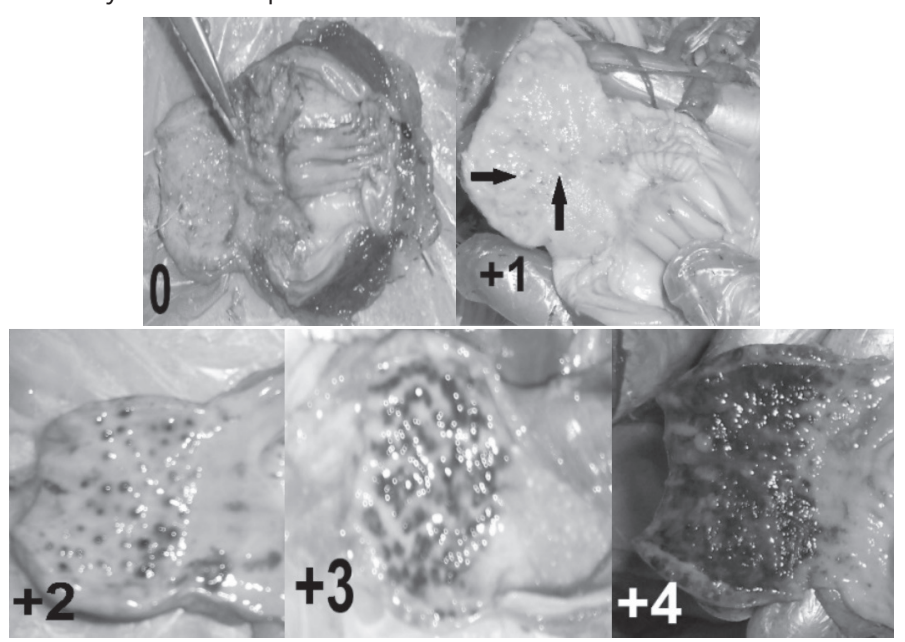

(0: healthy,+1 : pinpoint hemorrhage, +2 : intermediate hemorrhage, +3 : severe hemorrhage, +4 : very severe hemorrhage)
Figure 3 - Representative samples showing different severity scores in cecal tonsils

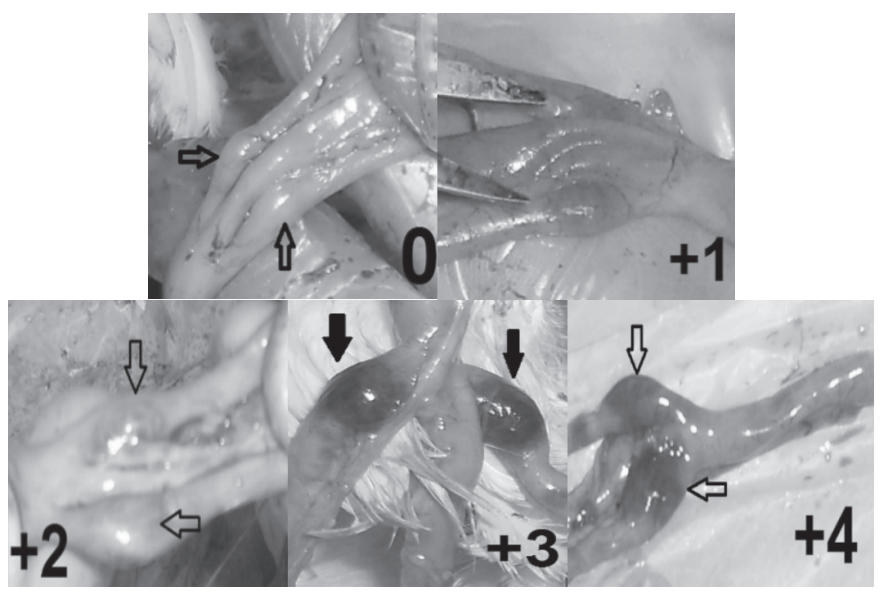

(0: healthy, +1 : mild congestion, +2 : moderate necrosis and hemorrhagic lesions, +3 : sever necrosis and hemorrhagic lesions, +4 : very sever necrosis and hemorrhagic lesions)

Figure 4 - Hemorrhagic lesions in the lymphoid aggregates of intestine which only observed in serosal $(A)$ and mucusal (B) surfaces of intestines in positive control group (group 7).

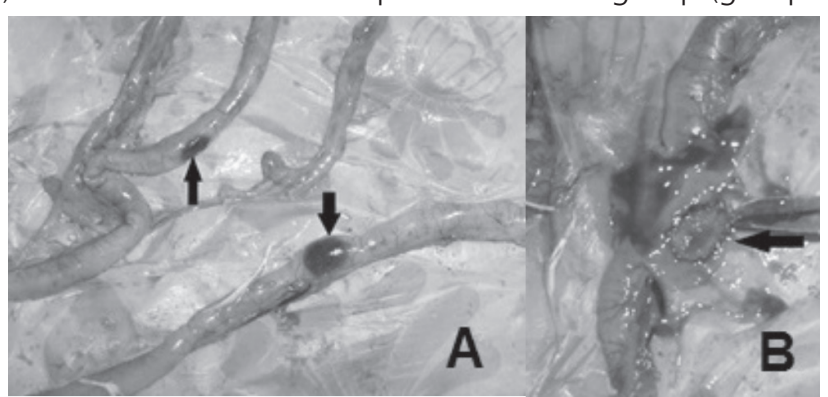

Figure $\mathbf{5}$ - Representative samples showing different severity scores in trachea [+4 index was not observed in this study].

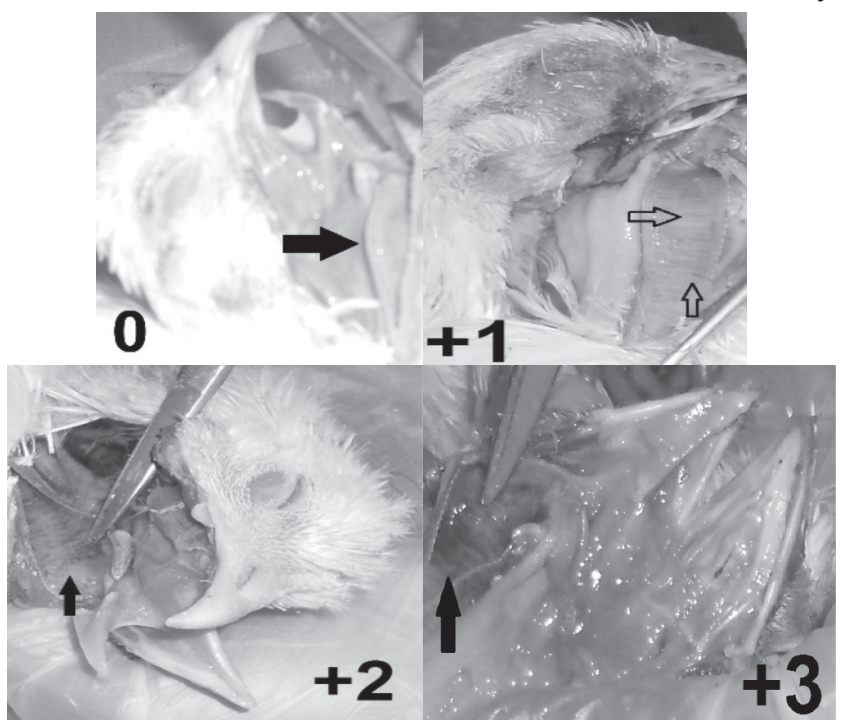

( 0 : healthy, +1 : mild congestion, +2 : intermediate congestion and hemorrhage,+3 : severe congestion and hemorrhage)

\section{Serological findings}

Mean $\left(\log _{2} \pm \mathrm{SE}\right)$ of serum antibody titers against NDV antigen at 1, 8, 15, 22, 28, 33, 38 and 42 days of age in all groups are presented in Table 2. 
Table 2 - HI antibody titers (means \pm SE) in all groups in different days.

\begin{tabular}{lcccccccc}
\hline $\begin{array}{l}\text { Days } \\
\text { Groups }\end{array}$ & 1 & 8 & 15 & 22 & $\begin{array}{c}28 \\
(0 \mathrm{pc})\end{array}$ & $\begin{array}{c}33 \\
(5 \mathrm{pc})\end{array}$ & $\begin{array}{c}38 \\
(10 \mathrm{pc})\end{array}$ & $\begin{array}{c}42 \\
(14 \mathrm{pc})\end{array}$ \\
\hline 1 & $6.9 \pm 0.95^{\mathrm{a}}$ & $5.2 \pm 0.37^{\mathrm{a}}$ & $4.7 \pm 0.25^{\mathrm{a}}$ & $5.4 \pm 0.4^{\mathrm{a}}$ & $5.2 \pm 0.2^{\mathrm{a}}$ & $6.4 \pm 0.24^{\mathrm{a}}$ & $5.4 \pm 0.24^{\mathrm{ab}}$ & $5.4 \pm 0.97^{\mathrm{a}}$ \\
\hline 2 & $6.9 \pm 0.95^{\mathrm{a}}$ & $5.4 \pm 0.4^{\mathrm{a}}$ & $4 \pm 0.31^{\mathrm{a}}$ & $5 \pm 0.31^{\mathrm{a}}$ & $5.4 \pm 0.4^{\mathrm{a}}$ & $6^{\mathrm{a}}$ & $7.8 \pm 0.73^{\mathrm{a}}$ & $8.2 \pm 0.48^{\mathrm{b}}$ \\
\hline 3 & $6.9 \pm 0.95^{\mathrm{a}}$ & $6.8 \pm 0.2^{\mathrm{b}}$ & $4.6 \pm 0.67^{\mathrm{a}}$ & $4.2 \pm 0.58^{\mathrm{a}}$ & $5.2 \pm 0.37^{\mathrm{a}}$ & $4.8 \pm 0.2^{\mathrm{b}}$ & $7.8 \pm 0.96^{\mathrm{a}}$ & $10^{\mathrm{b}}$ \\
\hline 4 & $6.9 \pm 0.95^{\mathrm{a}}$ & $6.6 \pm 0.24^{\mathrm{b}}$ & $5.2 \pm 0.2^{\mathrm{a}}$ & $4 \pm 0.63^{\mathrm{a}}$ & $5.8 \pm 0.48^{\mathrm{a}}$ & $4.6 \pm 0.24^{\mathrm{b}}$ & $8.4 \pm 0.87^{\mathrm{a}}$ & $9.4 \pm 0.4^{\mathrm{b}}$ \\
\hline 5 & $6.9 \pm 0.95^{\mathrm{a}}$ & $5.2 \pm 0.25^{\mathrm{a}}$ & $5 \pm 0.31^{\mathrm{a}}$ & $5 \pm 0.31^{\mathrm{a}}$ & $5.2 \pm 0.2^{\mathrm{a}}$ & $4.8 \pm 0.37^{\mathrm{b}}$ & $6.2 \pm 1.06^{\mathrm{a}}$ & $9.2 \pm 0.48^{\mathrm{b}}$ \\
\hline 6 & $6.9 \pm 0.95^{\mathrm{a}}$ & $5.2 \pm 0.25^{\mathrm{a}}$ & $5.2 \pm 0.37^{\mathrm{a}}$ & $4.8 \pm 0.66^{\mathrm{a}}$ & $6.8 \pm 0.37^{\mathrm{a}}$ & $4.4 \pm 0.24^{\mathrm{b}}$ & $8.4 \pm 0.4^{\mathrm{a}}$ & $9.2 \pm 0.37^{\mathrm{b}}$ \\
\hline 7 & $6.9 \pm 0.95^{\mathrm{a}}$ & $5.2 \pm 0.25^{\mathrm{a}}$ & $4.6 \pm 0.24^{\mathrm{a}}$ & $3.7 \pm 0.25^{\mathrm{a}}$ & $2.8 \pm 0.2^{\mathrm{b}}$ & $3^{\mathrm{c}}$ & $3^{* \mathrm{~b}}$ & - \\
\hline 8 & $6.9 \pm 0.95^{\mathrm{a}}$ & $5 \pm 0.4^{\mathrm{a}}$ & $4.4 \pm 0.24^{\mathrm{a}}$ & $3.6 \pm 0.24^{\mathrm{a}}$ & $2.4 \pm 0.24^{\mathrm{b}}$ & $2.2 \pm 0.2^{\mathrm{c}}$ & $2.4^{\mathrm{b}}$ & $2.6 \pm 0.24^{\mathrm{c}}$ \\
\hline
\end{tabular}

abc Different superscript letters denote significantly differences $(p \leq 0.05)$ in each column.

*only one bird was alive on day 10 pc in this group.

Maternal $\mathrm{HI}$ titers were reduced from 6.9 on day one to $<3 \log _{2}$ on the day of challenge in both control groups, and were not able to protect the chickens in the positive control group against ND infection. The antibody titers at 8 days of age in groups 3 and 4 , which received the $\mathrm{B} 1$ vaccine via eye drop at day-old, were significantly higher than other groups. However, no significant differences in antibody titers were observed at 15 and 22 days of age among groups. The antibody titer at 28 days of age (the day of challenge) was significantly $(p \leq 0.05)$ higher in all vaccinated groups ( $>$ $\left.5 \log _{2}\right)$ in comparison with control groups, which is an adequate antibody level to protect chickens from overt clinical disease. On day of challenge, all vaccinated groups had statistically the same $\mathrm{HI}$ antibody level. In groups 3, 4, 5 and 6, the antibody levels declined (but were potentially enough to protect chickens against the disease) after a short period post-challenge (5 $\mathrm{dpc}$ ), while the antibody titers increased in groups 1 and 2. No significant difference was observed among vaccinated groups $10 \mathrm{dpc}$. The antibody titers in groups $2,3,4,5$ and 6 were significantly higher than group 1 at 42 days of age ( $14 \mathrm{dpc}$ ). The mean antibody titer reached a peak in all vaccinated groups (except group 1) at 14 days post-vaccination.

\section{Virus shedding}

The results of virulent virus shedding in the fecal samples of all groups are summarized in Table 3. All samples from the non-vaccinated-unchallenged group were void of vaccine or virulent virus during the whole sampling period. The virulent virus was detected in birds of all vaccinated groups as well as positive control group from day $3 \mathrm{pc}$. The duration of virus shedding in the vaccinated challenged groups was different among groups. The shortest virus shedding period was recorded in groups 1 and 4, which shed the virulent virus up to $6 \mathrm{dpc}$. The other vaccinated groups, as well as unvaccinated-challenged group, shed the virulent virus in the feces until the end of the experiment. As shown in Table 3, no significant differences were observed in the rate of fecal virulent virus detection among challenged-vaccinated groups and the positive control group on different dpc.

Table 3 - Comparison of viral detection in feces of broilers in different groups of the experiment days post challenge.

\begin{tabular}{lllll}
\hline \multirow{2}{*}{ Groups } & \multicolumn{4}{c}{ Days post challenge } \\
\cline { 2 - 5 } & 3 & 6 & 9 & 14 \\
\hline 1 & $1 / 5^{\mathrm{ab}}$ & $2 / 5^{\mathrm{a}}$ & $0 / 5^{\mathrm{a}}$ & $0 / 5^{\mathrm{a}}$ \\
\hline 2 & $3 / 5^{\mathrm{ab}}$ & $3 / 5^{\mathrm{a}}$ & $1 / 5^{\mathrm{a}}$ & $1 / 5^{\mathrm{a}}$ \\
\hline 3 & $1 / 5^{\mathrm{ab}}$ & $3 / 5^{\mathrm{a}}$ & $0 / 5^{\mathrm{a}}$ & $1 / 5^{\mathrm{a}}$ \\
\hline 4 & $4 / 5^{\mathrm{a}}$ & $2 / 5^{\mathrm{a}}$ & $0 / 5^{\mathrm{a}}$ & $1 / 5^{\mathrm{a}}$ \\
\hline 5 & $3 / 5^{\mathrm{ab}}$ & $3 / 5^{\mathrm{a}}$ & $0 / 5^{\mathrm{a}}$ & $1 / 5^{\mathrm{a}}$ \\
\hline 6 & $4 / 5^{\mathrm{a}}$ & $2 / 5^{\mathrm{a}}$ & $3 / 5^{\mathrm{a}}$ & $1 / 5^{\mathrm{a}}$ \\
\hline 7 & $2 / 5^{\mathrm{ab}}$ & $3 / 5^{\mathrm{a}}$ & $2 / 2^{\mathrm{a}}$ & $\mathrm{NS}$ \\
\hline 8 & $0 / 5^{\mathrm{b}}$ & $0 / 5^{\mathrm{a}}$ & $0 / 5^{\mathrm{a}}$ & $0 / 5^{\mathrm{a}}$ \\
\hline
\end{tabular}

* Number of birds with virulent virus / total samples taken. NS: no survivors.

Different superscript letters denote significant differences $(p<0.05)$ in a column.

\section{DISCUSSION}

In Iran, the velogenic ND has been is enzootic in commercial poultry for years, despite the intensive vaccination programs applied. Annual losses due to the disease and cost-related preventive strategies raises the need of evaluating the emergence of virulent NDV and continuous research on vaccine type and efficacy of vaccines against circulating NDV. In this study, we assessed whether the currently used vaccines under different vaccination schemes could induce effective immunity in chickens against a virulent field isolate.

No clinical signs or virus excretion were observed in any birds of the uninfected control group. The unvaccinated-challenged birds demonstrated clinical signs and gross lesions of the disease, as well as virus shedding from $3 \mathrm{dpc}$, and finally all died (100\% mortality). The low maternal antibody titers (mean $<3$ 
$\log _{2}$ ) detected on the day of challenge were not able to protect susceptible chickens in this group from death. As we know, over time, maternal antibody titer wanes and eventually cannot protect against infections with wild viruses. Similar findings were reported by Fentie et al. (2014) and Kapczynski \& King (2005). This confirms that circulating vNDV strains are capable of causing high mortality in unvaccinated susceptible flocks, which is consistent with the suggestions of Alexander et al. (2004) and Alders \& Spradbrow (2001). Despite the expectation that mean antibody titers increased a week after challenge (Fentie et al., 2014; Alexander et al., 2004), substantial changes were not observed in the $\mathrm{HI}$ antibody titers in the sera of the positive-control group. This may be explained by the small serum sample size (only one bird of the positive control group was alive on $10 \mathrm{dpc}$ ).

Although all vaccinated groups had significantly lower mortality rate than unvaccinated-challenged group, full protection from death was only observed in birds of group 1 (no mortality) followed by group 2 with 5\% mortality. In general, the best protection against death was observed in groups 1 and 2 , respectively. Other vaccinated groups that received the live B1 vaccine at one day of age showed 75 to $90 \%$ protection against circulating vNDV. Partial protection against the disease in these groups may be explained by the inhibitory effect of high maternal antibody titers on live vaccine at day old. Maternal antibodies suppress vaccine-induced immune responses (Niewiesk, 2014).

A comparison on the beginning and severity of the clinical signs of the disease among different groups demonstrated that all vaccinated-challenged groups showed clinical signs later (from day 5 pc) and less severe than the unvaccinated-challenged group. In addition, necropsy findings revealed that lesions were less severe in all vaccinated groups as compared with positive control group. Protection against clinical signs and mortality following infection with vNDV in vaccinated birds has also been reported by other researchers (Boven et al., 2008, Fentie et al., 2014, Kapczynski \& King, 2005, Degefa et al., 2004).

Among vaccinated groups, the best results with regards to clinical signs and gross lesions were obtained in groups 1 and 2. Vaccination provided high $\mathrm{HI}$ antibody titers in the vaccinated groups, which is in consistent with the reports of Boven et al. (2008) and Kapczynski \& King (2005). Evaluation of HI antibody titers in vaccinated-challenged groups during the experiment demonstrates that all vaccination programs were able to induce adequate antibody levels to provide protection against the circulating virus. On day of challenge, the mean $\mathrm{HI}$ titer of all vaccinated groups was higher than $5 \log _{2}$ and remained high until the end of the experiment, which was sufficient to protect birds from overt clinical signs. As previously described, mean $\mathrm{HI}$ antibody titers higher than $3 \log _{2}$ have a protective role against NDV (Boven et al., 2008, Kapczynski \& King, 2005).

While some birds in the vaccinated-challenged groups were protected from clinical disease and mortality, they were not protected against infection, since they shed challenged virus in fecal samples. Our findings are consistent with the reports of Fentie et al. (2014), Boven et al. (2008), and Kapczynski \& King (2005). The chickens in all vaccinated-challenged groups shed the challenge virus from day $3 \mathrm{dpc}$. These prime-boost immunized chickens continued to shed the virus. Insignificant differences in the frequencies of virus detection among vaccinated groups and positive control reveals that different vaccination programs and type of vaccine were not able to protect the chickens against virus infection and replication. However, the incidence and duration of virulent virus shedding in infected birds of vaccinated groups were different. Vaccination programs used in groups 1 and 4 shortened the duration of virus shedding (until day $6 \mathrm{pc}$ ), while few of the challenged birds in the other vaccinated groups continued to shed the virulent virus in the feces until the end of the experiment. Similar findings were reported by Fentie et al. (2014) and Kapczynski \& King (2005). The high antibody levels in the vaccinated challenged groups may have been responsible for the reduced virulent virus shedding. Therefore, despite vaccination, NDV re-infection of susceptible birds with lower immunity in a flock occurs in field conditions. This may explain the increase in frequency of vaccinations throughout the rearing period of broiler chickens, which has been applied by some farmers. The higher antibody titers at $10 \mathrm{dpc}$ in comparison with other vaccinated groups may explain the lower virus shedding in group 1. At the end of the experiment (14 days after challenge), chickens showed more than $8 \log _{2}$ mean $\mathrm{HI}$ antibody titer, except for group 1, which $\mathrm{HI}$ titer tended to decline after the tenth day post challenge. The increase in mean $\mathrm{HI}$ titers in these groups two weeks after challenge may be due to immune system response following continuous virus replication and shedding until the end of the study period.

These findings indicate that, although the vaccination programs used in Iran can protect broilers 
Comparative Evaluation of The Protective Efficacy of Different Vaccination Programs Against a Virulent Field Strain of the Newcastle Disease Virus in Broilers from overt disease and high mortality following challenge with the highly virulent NDV, chickens are not fully protected against circulating virulent virus infection and act as virus reservoirs. The administration of the live B1 vaccine via ocular route concurrent with oil-emulsified vaccine at 8 day of age and the boost vaccination with a lentogenic live virus may be able to induce efficient local and humoral immunity responses and therefore, better protection against infection. Since partial to high protection of vaccines and different vaccination programs against a field isolate of vNDV was evaluated in the current study, it is likely that the failure to protect the commercial broiler flocks against circulating VNDV in the field may be due to various factors, such as the presence of immunosuppressive etiologic agents that cause lack of response or inadequate response to the vaccine; vaccination failures, including improper handling and vaccine administration; poor management practices in poultry flocks, etc., rather than lack of potency of product. In addition, changes in field virus characteristics may play a role in the partial protective efficiency of the vaccination programs.

\section{ETHICAL APPROVAL}

All experiments in this study were performed in accordance with the guidelines for animal research from the School of Veterinary Medicine, Shiraz University, Shiraz, Iran, and the recommendations of European Council Directive (2010/63/EU).

\section{ACKNOWLEDGEMENTS}

This research was supported by Shiraz University and Razi Vaccine and Serum Research Institute, Shiraz, Iran.

\section{REFERENCES}

Alders RG, Spradbrow PB. Controlling Newcastle disease in village chickens: a field manual. Canberra: Australian Centre for International Agricultural Research; 2001. 112p

Aldous EW, Mynn JK, Banks J, Alexander DJ. A molecular epidemiological study of avian paramyxovirus type 1 (Newcastle disease virus) isolates by phylogenetic analysis of a partial nucleotide sequence of the fusion protein gene. Avian Pathology 2003;32:239-256.
Alexander DJ, Aldous EW, Fuller CM. The long view: a selective review of 40 years of Newcastle disease research. Avian Pathology 2012;41(4):329335 .

Alexander DJ, Bell JG, Alders RG. A Technology review: Newcastle disease with special emphasis on its effect on village chickens [animal production and health papers 161]. Rome: Food \& Agriculture Organization of the United Nations; 2004.

Alexander DJ. Newcastle disease and other paramyxoviradae infections. In: Calnek BW, Barnes CW, Beard LR, McDougald LR, Saif YM, editor. Diseases of poultry. Ames: lowa State University Press; 1997. p.69-541.

Alexander DJ. Newcastle disease in the European Union 2000 to 2009 Avian Pathology 2011;40(6):547-558.

Baratchi S, Ghorashi SA, Hosseini M, Pourbakhsh SA. Differentiation of virulent and non-virulent Newcastle disease virus isolates using RT-PCR. Iranian Journal of Biotechnology 2006;4(1):61-63.

Boney WA, Stone HD, Gillette KG, Coria MF. Viscerotropic velogenic Newcastle disease in turkeys: immune response following vaccination with either viable B1 strain or inactivated vaccine. Avian Diseases 1975;19(1):19-30.

Boven MV, Bouma A, Fabri THF, Katsma E, Hartog L, Koch G. Herd immunity to Newcastle disease virus in poultry by vaccination. Avian Pathology 2008;37(1):1-5

Degefa T, Dadi L, Yami A, Mariam KG, Nassir M. Technical and economic evaluation of different methods of Newcastle disease vaccine administration. Journal of Veterinary Medicine 2004;51:365-369.

Fentie T, Dadi K, Kassa T, Sahle M, Cattoli G. Effect of vaccination on transmission characteristics of highly virulent Newcastle disease virus in experimentally infected chickens. Avian Pathology 2014; 43(5):420426.

Giambrone JJ, Closser J. Effect of breeder vaccination on immunization of progeny against Newcastle disease. Avian Diseases 1990;34(1):114119.

Kapczynski DR, King DJ. Protection of chickens against overt clinical disease and determination of viral shedding following vaccination with commercially available Newcastle disease virus vaccines upon challenge with highly virulent virus from the California 2002 exotic Newcastle disease outbreak. Vaccine 2005;23:3424-3433.

Niewiesk S. Maternal antibodies: clinical significance, mechanism of interference with immune responses, and possible vaccination strategies. Frontiers in Immunology 2014;5:446.

OIE. Manual of diagnostic tests and vaccines for terrestrial animals: mammals, birds and bees. Paris: Biological Standards Commission; 2012. v.1, p.1-19.

Patti J. Miller, Koch G. Newcastle disease. In: Swayne DE, Glisson JR, McDougald LR, Nolan LK, Suarez DLO, Nair VN, editors. Diseases of poultry. $13^{\text {th }}$ ed. Athens: John Wiley \& Sons; 2013. p.89-107.

Reed LS, Muench LH. A simple method of estimating fifty percent endpoints. The American journal of Hygiene 1938;27:493-497. 
